\title{
Early Intervention and Prevention
}

Alcohol and Drug Prevention Briefing Paper

This briefing paper is part of a series produced by Mentor ADEPIS on alcohol and drug education and prevention, for teachers and practitioners.

\section{Questions for schools}

\section{What is Early Intervention}

\section{How does it work?}

\section{What does Early Intervention mean for schools?}

All schools and educators have the statutory obligation to promote children's well-being and develop a healthy environment in which they can thrive.

There are various factors influencing children's well-being, and these include the environment they grow up in, the various types of relationships shaping their lives, the educational environment, the individual process of identity construction, including the development of self-belief and selfesteem. Indeed all these factors are interrelated and mutually determined.

Recent studies have highlighted that during the early years of children's lives (from conception to primary school), related life experiences, as well as relationships and competencies developed within these early life stages, have a major impact on health and the well-being outcomes of later life.

When children and young people are given the necessary support to develop social and emotional skills through positive parenting and a supportive educational environment, it is more likely that they will have improved educational, career and life outcomes.

Early Intervention and prevention programmes afford a real opportunity for children and young people to develop essential social and emotional abilities to better face future challenges and experiences, and to prevent persistent social problems deriving from individuals' poor well-being and the resulting limited life opportunities.

\section{Review:}

This briefing paper draws on evidence provided by governmental sources, such as the latest Chief Medical Officer's report, and an independent report to Her Majesty's Government undertaken by Graham Allen MP, as well as academic sources reviewing evidence-based educational programmes. We also looked closely at evidence-based programmes that have been evaluated as effective in promoting positive social and emotional outcomes for children and young people, through online resources such as The Early Intervention Foundation (EIF) and The Centre for Analysis of Youth Transitions (CAYT).

\section{Children's development}

"Every child deserves the best possible start in life and the support that enables 
them to fulfil their potential. Children develop quickly in the early years and a child's experiences between birth and age five have a major impact on their future life chances. A secure, safe and happy childhood is important in its own right. Good parenting and high quality early learning together provide the foundation children need to make the most of their abilities and talents as they grow up". 1

Research around human brain development suggests that babies are born with 25 per cent of their brain developed and that the first three years of their lives are essential to further develop it up to 80 per cent. ${ }^{2}$ It is therefore crucial that, during these years, toddlers receive fundamental emotional support to shape their development. Any form of neglect or dysfunctional parenting may deeply impact on their future attitudes and emotional stability.

But whilst positive parenthood plays a fundamental role in ensuring children's well-being, formal education settings specifically the years of nursery and primary school - are also key environments which shape the way children and young people will respond to life challenges once they are grown up. ${ }^{3}$

Formal education in nurseries and primary schools can not only strengthen the social and emotional skills already provided by parents, but also correct potential dysfunctional problems experienced by young children born in relatively unstable environments, where neglect, mental illhealth or violence may be present.

Acting later in the young person's life (during or post-adolescence), or when problems are already formed (late intervention or rehabilitation) may be too late and not as effective as intervening in early stages, as individuals' socioemotional responses to life challenges and risks are already shaped, and behavioural changes may be problematic.

Early social development programmes, alongside Personal, Social, Health and Economic education, have an outstanding role in promoting children and young people's well-being, due to their preventative attributes.

\section{What is prevention?}

Within this context, prevention is the promotion of constructive lifestyles, norms and relationships aimed at discouraging attitudes, values or behaviours leading to damaging social problems or issues.

Prevention as an approach addresses protective and risk factors influencing children and young people's lives. In previous papers ${ }^{4}$ we highlighted how various risk factors in combination increase the chances of an individual's involvement in risky or anti-social behaviours. A 2007 review, which looked at better supporting children and families, also proved that protective factors increase the chances of positive life outcomes, subsequently encouraging resilience. ${ }^{5}$

Risk and protective factors are normally inter-connected and mutually determined therefore programmes aimed at strengthening one particular protective factor have major impacts in boosting related protective factors, building young people's resilience and self-esteem. High attainment, good social and emotional skills and positive parenting, for instance, are considered to be essential, and mutually supportive: positive parenting and good social and emotional skills are likely to encourage high attainment levels. ${ }^{6}$

Prevention works on strengthening protective factors shaping young people's lives, promoting positive social norms, whilst ultimately strengthening young people's resilience to risk.

\section{What is Early Intervention?}

In recent years the term 'early intervention' has been used to define a vast range of activities, and has led to wide ranging discussion aimed at determining what early intervention is, and how it relates to wider prevention. Differentiating between prevention and early intervention is not easy; in fact many programmes can be considered as both early intervention and prevention measures. In this paper we will refer to both early intervention and prevention programmes, and consider the former as a form of prevention.

Early intervention is characterised by the ability to intervene as early as possible (in 
the early years of a child's life) to tackle problems that may have emerged in children and young people identified as 'in need for additional support'. The Early Intervention Foundation defines Early Intervention as programmes, practices and systems that support targeted action to prevent social cost and personal harm for children and young people, anywhere from conception to early adulthood. Early intervention thus prevents children and young people from experiencing serious or enduring problems. $^{7}$

\section{Why Early Intervention?}

'Early Intervention is about addressing the root causes of social disadvantage, ensuring that everyone is able to realise their full potential by developing the range of skills we all need to thrive. It is about getting extra, effective and timely interventions to all babies, children and young people who need them, allowing them to flourish and preventing harmful and costly long-term consequences' (Early Intervention Foundation).

On the basis of the significant impact that events occurring early in life have on the health and wellbeing of individuals in their future attitudes and life choices, the Chief Medical Officer's annual report stressed the value of, and recommended the promotion of evidence-based early interventions to tackle social and health inequalities.

Research emphasised that early intervention programmes, focused on 0-18 year olds, enable children to grow into young people and young adults with the social and emotional skills they need to learn and make effective choices about life. $^{8}$

Early intervention and social development programmes aimed at developing children's social and emotional capabilities proved to be effective in reducing antisocial or violent behaviour throughout life and improving young people's resilience, educational attainment, health, and social and economic outcomes, consequently enabling intra-generational social mobility. ${ }^{9}$
Early intervention programmes could significantly reduce costs related to correcting social or public health issues by reducing truancy, antisocial behaviour, crime, health problems, welfare dependency, the need for statutory social care, under attainment, exclusion from school and the need for educational alternative provision. ${ }^{10}$

\section{How does early intervention work?}

Early Intervention programmes, if delivered at different stages of an individual's life, can create a virtuous circle, which prepares children and young people for their future lives. Early intervention programmes not only support the development of all children but also reduce social and health inequalities, providing developmental opportunities to the most disadvantaged and vulnerable individuals.

Children who grow up in dysfunctional environments are more likely to recreate such environments themselves later in their lives, developing an inter-generational cycle of dysfunction, a positive feedback loop or vicious circle. This cycle of dysfunction can be interrupted through achieving positive and inter-connected outcomes established through complementary early intervention programmes.

Alcohol and drug education, as well as educational programmes aimed at developing children's and young people's social and emotional skills, should be delivered through the process of a spiral curriculum: a curriculum that - as it develops - revisits basic ideas repeatedly, and builds upon them until the student masters the underlying principles that go with them. ${ }^{11}$

Early intervention programmes delivered through a spiral curriculum allow the development of children and young people's emotional intelligence through social and emotional learning. Emotional intelligence is the ability to monitor one's own and others' feelings and emotions, as well as the ability to appropriately use emotions to guide thoughts and actions. ${ }^{12}$

Social and emotional learning involves the processes through which children and 
young adults develop and effectively master the knowledge, skills and attitudes needed to understand and manage emotions, set and achieve positive goals, understand, feel and demonstrate empathy for others, establish and maintain positive relationships, and make responsible decisions. $^{13}$

Emotional Intelligence development is defined and built through four main competences:

- Self-awareness: the ability to recognise one's emotions, thoughts and their influence on behaviour;

- Self-management: the ability to regulate one's emotions, thoughts, and behaviours effectively in various situations (this includes managing stress, controlling impulses and motivating oneself);

- Social awareness: the ability to empathise with others, understanding positive ethical and social norms of behaviour, and ability to recognise sources of support (e.g. within the family, school or community);

- Relationship management: the ability to develop and maintain healthy and rewarding relationships, make constructive and respectful choices about personal behaviour and social interactions, resisting inappropriate social or peer pressure, negotiating conflict constructive and building good communication skills. ${ }^{14}$

These core competences contribute to the development of resilient and responsible individuals, ultimately having an influence on attitudes and decisions children and young people will have to take when facing challenging situations, risk factors, and difficult relationships with others.

The figure below shows key stages in an individual's life, for which there are different and appropriate Early Intervention measures. When implemented together and in conjunction with a spiral curriculum, these measures allow the development of essential social and emotional skills that build on an individual's ability to make informed and responsible choices, contributing to breaking potential dysfunctional cycles.

It is only by providing children with the basic foundation of social and emotional skills, and by further developing them throughout their lives as children, adolescents and young adults that we can ensure that they are school ready, life ready and child ready. ${ }^{15}$

Figure I.I: A virtuous circle

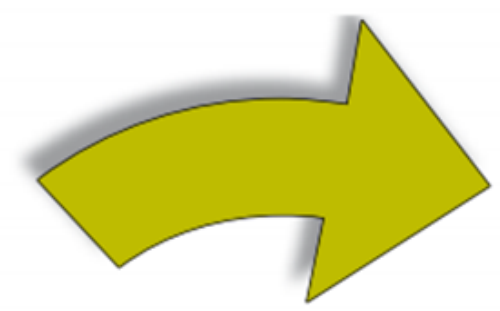

Child ready

-9 months to 0 School ready $3-5$ years

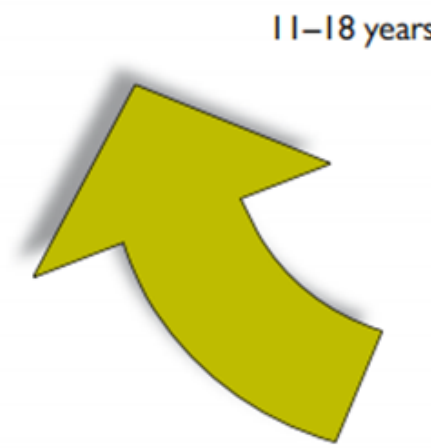

Life ready

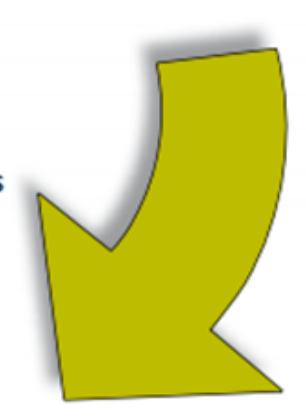




\section{What does this mean for schools?}

A report commissioned by the Department for Education stressed that children with higher levels of emotional wellbeing have higher levels of school achievement. ${ }^{16}$ Likewise, a 2004 study aimed at assessing students' emotional intelligence revealed a strong correlation between high emotional intelligence scores and high levels of academic achievement. ${ }^{17}$

Early social and emotional development programmes help to increase attachment to school, improve academic performance, improve social skills, and reduce aggressive and disruptive behaviour in and outside the classroom.

In practice this can be translated into fewer disruptive toddlers, fewer unmanageable school children and fewer young people engaging in risky or anti-social behaviours ${ }^{18}$ - which in the long term will improve classroom management, staff retention in schools and life in the local communities.

\section{Early intervention that works}

Age-appropriate social and emotional skills help children and young people make more positive life choices. For this reason, the foundation given to children in their early years should be further reinforced during primary and secondary school years.

Evidence-based intervention programmes for schools normally take the form of annexes or amendments to school curricula, lasting between a few weeks and several years. ${ }^{19}$

Below we have listed a series of Early Intervention and prevention evidencebased programmes that have been evaluated as effective in preventing a variety of risky behaviours. The examples are not only intended to address the use and misuse of alcohol and drugs, but also to prevent risky sexual behaviours, antisocial or violent behaviours and bullying, whilst enhancing school engagement and educational attainment.

\section{Universal}

Positive Action

Age group: 6-17

Intended Outcomes: Reduce substance misuse, prevent violent or antisocial behaviour, enhance school achievement, prevent risky sexual behaviour

Positive Action is an evidence-based early intervention programme structured into 1520 minutes sessions (for a total amount of 35 hours per year) to be integrated within the mainstream curriculum. Positive Action is suitable for children from reception through to the end of secondary school, as different iterations of the programme exist for specific age groups. The intervention is based on the assumption that children will behave in a positive way when they feel good about themselves. The programme explores actions that help children to feel better about themselves within three key areas: personal, social and environmental.

Outcomes: In the short term children have greater self-esteem, increased motivation to learn, and improved social and emotional skills. In the long term young people will be less engaged in violent and substance misusing behaviours and more engaged with school.

\section{The Good Behaviour Game}

\section{Age group: 6-10}

Intended Outcomes: Prevent substance misuse, prevent risky sexual behaviour, and prevent violent and antisocial behaviour.

The Good Behaviour Game is an evidence -based early intervention programme based on a comprehensive social influence approach to manage class behaviour during lessons. Pupils are divided into teams and may earn prizes and praise by keeping simple rules for good behaviour. The sessions (on average 10 minutes) can be applied to a variety of classroom activities (e.g. writing a story, drawing a picture, doing maths).

Outcomes: Evaluation showed significant reduction in disruptive and aggressive behaviour and improvement in children's ability to focus and work independently. In the long term, the programme halves the 
probability of young men engaging in risky behaviours (e.g. drug abuse or dependence); increases the likelihood of high school graduation by $21 \%$ and of college attendance by $62 \%$. The programme also proves effective in reducing stress levels among teachers, consequently increasing staff retention. The Social Research Unit shows a cost:benefit ratio of 1:26.

Mentor has been appointed to lead a national randomised controlled trial of the Good Behaviour Game. Contact us to find out more.

The Olweus Bullying Prevention Programme (OBPP)

\section{Age group: 3-11}

Intended Outcomes: Prevent violent and antisocial behaviour

The Olweus Bullying Prevention Programme is based on the assumption that bullying is interdependent on and reinforced by a series of risk and protective factors affecting the child, the peer group, the classroom and the school. The programme promotes pro-social attitudes through activities addressing those risk and protective factors shaping bullying and antisocial behaviours. OBPP can be applied to a variety of classroom activities, as well as at school-wide and individual levels.

Outcomes: In the short term, the programme improves the school environment and pupils' attitudes towards anti-bullying, strengthening community awareness on bullying issues. In the long term, it reduces bullying and anti-social behaviour.

\section{DrugAware}

Intended Outcomes: Prevent substance misuse

Age group: Primary and secondary schools

DrugAware is an aspirational standard awarded to schools engaging in preventive activities aimed at discouraging substance misuse. The programme is based on the assumption that children are less likely to engage in dangerous substance misuse if they understand the risks associated to it, and if their school implements the right policies to respond to substance misuse without excluding pupils. DrugAware sets compliance standards and support for schools and teachers to develop and implement inclusive and effective drug curriculums and policies.

Outcomes: In the short term children have an increased awareness of risks associated to alcohol and drugs misuse, an increased resilience, and better skills to resist peer pressure. In the long term illegal substance misuse in schools is expected to decrease, and children are expected to have an increased school engagement and a lower involvement in anti-social behaviour.

\section{Targeted}

Incredible Years Child Training Programme (Dinosaur curriculum)

Intended Outcomes: Improve child behaviour

\section{Age group: 2-8}

This programme is aimed at addressing problematic child behaviour by directly teaching children strategies to manage their impulses, feelings and relationships with others. The programme is normally delivered by trained practitioners, who pull six to eight participants out of their classroom to attend a two hours session for a period of 18 to 20 weeks. The programme is based on the assumption that problematic child behaviour is due to coercive interactions with adults, who involuntarily reward negative child behaviour.

Outcomes: In the short term children behave better at school and at home. In the long term the child will get along better with others and will be less likely to engage in anti-social or criminal behaviour.

\section{Conclusion}

This briefing paper is aimed at informing teachers and practitioners involved in the delivery of alcohol and drug education and prevention. In the paper we set out the 
importance of early years' education whilst clarifying differences between Early Intervention and Prevention.

The use of rigorous methodology and evidence-based early intervention and prevention programmes will offer children and young people the opportunity to grow up with the social and emotional life skills to become responsible citizens and better parents.

Early intervention and prevention programmes, alongside with the delivery of Personal, Social, Health and Economic education, are one of the key steps to promote equal opportunities and developmental chances to all children.

If you wish to find out more information about evidence-based early intervention and prevention programmes please visit:

CAYT

Early Intervention Foundation

\section{References}

1. DfE, Statutory Framework for the Early Years Foundation Stage

2. Huttenlocher PR (1984) Synapse elimination and plasticity in developing human cerebral cortex. American Journal of Mental Deficiency 88(5): 488-96; Huttenlocher PR and Dabholkar AS (1997) Regional differences in synaptogenesis in human cerebral cortex. Journal of Comparative Neurology 387: 167-78.

3. Allen Graham MP, Early Intervention: The next steps https://www.gov.uk/government/uploads/ system/uploads/attachment data/file/284086/ early-intervention-next-steps2.pdf

4. Efficient needs assessment in schools http:// mentor-adepis.org/efficient-needs-assessmentschools/ and Making it inclusive: alcohol and drug education in multicultural settings http:// mentor-adepis.org/efficient-needs-assessmentschools/

5. HM Treasury and DfES, 2007, Aiming High for Children: Supporting Parents, http:// dera.ioe.ac.uk/7755/1/PU188.pdf

6. Ibid

7. Ibid

8. Allen Graham MP, Early Intervention: The next steps https://www.gov.uk/government/uploads/ system/uploads/attachment data/file/284086/ early-intervention-next-steps2.pdf

9. Call for evidence for the 'Social Mobility and Child Poverty Review', ESRC, http:// www.esrc.ac.uk/ images/ ESRC social mobility tcm8-18434.pdf

10.Ibid
11.Bruner, J (1960) The Process of Education, Cambridge, Mass.: Harvard University Press. $97+$ xxvi pages. Rightly recognized as a twentieth century educational 'classic', this book argues that schooling and curricula should be constructed to foster intuitive 'graspings'. Bruner makes the case for a 'spiral curriculum'. The second edition, 1977, has a a new preface that reassesses the book.

12.Illis, Developing Emotional Intelligence, http:// www.reframenow.com/pdfs/Developing\% 20Emotional\%20Intelligence.pdf

13.CASEL - http://www.casel.org/social-andemotional-learning

14.Illis, Developing Emotional Intelligence and CASEL - http://www.casel.org/social-andemotional-learning

15.Allen, Graham MP, Early Intervention: The next steps https://www.gov.uk/government/ uploads/system/uploads/attachment data/ file/284086/early-intervention-next-steps2.pdf

16. The impact of pupil behaviour and wellbeing on educational outcomes https://www.gov.uk/ government/uploads/system/uploads/ attachment data/file/219638/DFE-RR253.pdf

17.Parker, J.D.A., Creque, R.E., Barnhart, D.L., Harris, J.I., Majeski, S.A., Wood, L.M., Bond, B.J., \& Hogan, M.J. (2004). "Academic achievement in high school, does emotional intelligence matter?" Personality and Individual Differences, 37,1321-1330

18.Allen, Graham MP, Early Intervention: The next steps https://www.gov.uk/government/ uploads/system/uploads/attachment data/ file/284086/early-intervention-next-steps2.pdf

19.Ibid

Figure 1.1-Allen, Graham MP, Early Intervention: The next steps https://www.gov.uk/ government/uploads/system/uploads/ attachment data/file/284086/early-interventionnext-steps2.pdf

\section{About ADEPIS}

The Alcohol and Drug Education and Prevention Information Service is run by Mentor, the drug and alcohol protection charity, in conjunction with DrugScope and Adfam, and is funded by the Department for Education.

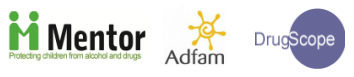

More resources and advice are available from mentor-adepis.org. For further information, contact:

ADEPIS c/o Mentor

$1^{\text {st }}$ Floor, 67-69 Cowcross Street

London EC1M 6PU

adepis@mentoruk.org

02075539920 